\title{
A mediatização de temáticas públicas via recomposição e circulação em rede de conteúdos de coberturas de crimes
}

Eloisa Klein ${ }^{1}$

\section{Resumo}

Analisamos a mediatização dos modos de posicionamentos no espaço público a partir da reconfiguração de conteúdos jornalísticos por indivíduos fora deste campo e da circulação de vídeos no YouTube. São analisados vídeos de homenagem às crianças Isabella Nardoni (morta em 2008) e Bernardo Boldrini (morto em 2014), que constroem um campo temático sobre a preservação da infância, pela comoção com o sofrimento da mãe que perde a filha, pela vida feliz interrompida, e pelo sofrimento em vida.

Palavras-chave: Mediatização; Jornalismo; YouTube; Espaço Público.

\section{Resumen}

Analizamos la mediatización de los modos de posicionamientos en el espacio públi $\neg c o$ a partir de la reconfiguración de contenidos periodísticos por individuos fuera de este campo y de la circulación de vídeos en el YouTube. Son analizados vídeos de homenaje a los niños Isabella Nardoni (muerta en 2008) y Bernardo Boldrini (muerto en 2014), que construyen un campo temático sobre la pre - servación de la infancia, por la conmoción con el sufrimiento de la madre que pierde la hija, por la vida feliz interrumpida, y por el sufrimiento en vida.

Palabras clave: Mediatización; Periodismo; YouTube; Espacio Público.

\begin{abstract}
${ }^{1}$ Professora da Universidade Federal do Rio Grande do Norte. Doutora e mestre em Ciências da Comunicação pela Universidade do Vale do Rio dos Sinos. Graduada em Comunicação Social - Jornalismo, com especialização em Humanidades, pela Universidade Regional do Noroeste do Rio Grande do Sul.
\end{abstract}



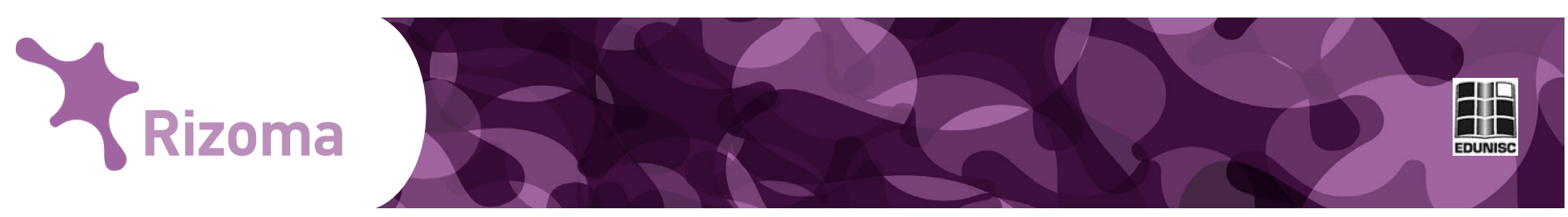

\section{Introdução}

Entre 2008 e 2011, ao estudar as processualidades do telejornalismo, com a finalidade de desenvolvimento de minha tese de doutoramento (KLEIN, 2012), acompanhei as coberturas de casos de grande repercussão social, às quais são dedicados maior tempo, recursos, número de repórteres, e nas quais há maior diversidade de abertura temática e aproximação do jornalismo com outros campos sociais. Em sua lógica midiática, estes casos se movimentam na mídia "por seu valor como notícia", com o que incidem sobre eles as lógicas narrativas (FORD, 1999, p. 246), que os fazem se desenvolver por um longo período de tempo, adquirindo uma larga abrangência na conversação de assuntos da vida coletiva e vivência da realidade social.

Com o intuito de observar as lógicas de circulação de notícias, fotos, vídeos jornalísticos, bem como a reverberação destes casos por pessoas fora do campo midiático empresarial. O site YouTube apareceu como repositório de matérias jornalísticas por pessoas comuns e também como espaço de recriação de conteúdos, com uma expressiva aparição de vídeos que tinham em comum o caráter de homenagem às vítimas de crimes. A partir do acompanhamento de algumas dezenas de vídeos, numa observação não controlada, foi possível caracterizar ângulos comuns transcendentes: a homenagem, a utilização de fotografias em grande quantidade e variedade (o que podenos fazer inferir um grande trabalho de busca, reunião e reaproveitamento de materiais) e a construção de um posicionamento ao espaço público, em busca da formação de opinião, a partir da compaixão. O posicionamento no espaço público via promoção da comoção foi o eixo escolhido para a análise neste artigo. Esse não ocorre a partir da mediação do jornalismo, de indústrias midiáticas, ou de outras instâncias institucionais de representação do indivíduo, como igrejas ou sindicatos, mas pela remixagem de materiais, elaboração audiovisual, modos de compartilhamento via ferramentas disponíveis em sites que abrigam conteúdos e criação de circuitos de propagação via fluxos de redes.

Floriani e Morigi (2006) analisam como este posicionamento das pessoas em atividades em qualquer "lugar virtual" faz com que potencialmente estes lugares se construam como espaços públicos, no sentido de tornarem-se espaço de poder, ação comum coordenada e com estratégias de persuasão. Trata-se de uma transformação considerável quando pensado um cenário em que a composição do espaço público dava-se predominantemente a partir das linguagens e ações de indústrias, profissionais e instituições do campo midiático-informativo, de acordo com seus padrões editoriais, interesses econômicos e ideológicos - conforme análise de Charaudeau (2006).

Este texto analisa aspectos de posicionamento no espaço público presentes em 14 vídeos feitos para homenagear crianças assassinadas por membros da família. Tais vídeos permitem a análise de aspectos de mediatização, como procedimentos de visibilidade midiática, estratégias narrativas fundamentadas na construção de personagens, com composição feita com fotos e 
materiais audiovisuais, adoção da linguagem do entretenimento, com imagens modificadas, editadas, som ambiente e trilha sonora. A reconfiguração de conteúdos jornalísticos aparece como característica central, na lógica do que se entende como "remixagem" nas produções acadêmicas sobre redes digitais, tendo em conta um "conjunto de práticas sociais e comunicacionais de combinações, colagens" e cortes de informações "a partir de tecnologias digitais" (LEMOS, 2005). Na composição textual destes conteúdos, há ênfase para vídeos musicais, mensagens religiosas e textos de conforto à dor de famílias que ficaram conhecidas por perderem membros de forma trágica.

Ainda que acionem elementos de entretenimento, tais vídeos trabalham aspectos de visibilização de temas do presente vivido, dialogando com lógicas jornalísticas, desde a captação de material, lógicas narrativas, acionamento de informação e proposição pública com fundamento no conhecimento de um problema e promoção da comoção. Em realidades nas quais há predominância dos sistemas midiáticos informacionais na articulação do espaço público, a linguagem jornalística se apresentava "como tendencialmente homogeneizadora e adequada à formação de consensos sociais através da observação, classificação e denúncia de tudo o que se afigura como desviante em relação à norma" (CORREIA, 2000, p. 193). Em contexto de redes digitais de construção e circulação de conteúdos, os vídeos aqui analisados, também se posicionam na construção de um campo temático que reflete sobre a preservação da infância, pela comoção com o sofrimento (1) da mãe que perde a filha e da vida feliz interrompida, no caso Isabella ${ }^{2}$, e (2) da comoção pelo conhecimento público da condição de sofrimento em vida, no caso Bernardo ${ }^{3}$.

\section{Interações mediatizadas e tecnologias}

Pensamos a midiatização como um processo social em que as tecnologias e os circuitos midiáticos passam a compor a base de ação das instituições, penetram as interações e a vida cotidiana, com alteração nos "processos sociotécnico-discursivos de produção, circulação e de recepção de mensagens" (FAUSTO NETO, 2008). Estas alterações transformam as matrizes de comunicação e cultura (MARTÍN-BARBERO, 1997), afetando nossa percepção da realidade, espaço e tempo (que passa a incorporar informações sobre o mundo todo, bem como a referência a mundos imaginados, presentificados pela mídia). Há também alterações na relação entre indivíduos e instituições. O processo de mediatização vem sendo marcado pelo "rearranjo e construção de campos", "dificuldade de percepção de papéis sociais", ausência de articulações entre as "interações mediatizadas, tipo de acessibilidade ao sentido da realidade e da subjetividade do indivíduo" (BRAGA, 2006, p.11- 15).

Nesta crescente participação dos processos midiáticos na organização da sociedade, Verón (2001) analisa que a televisão exerceu um grande papel, por possibilitar a predominância de características simbólicas e indiciais, e pela disseminação de conteúdos para grandes públicos, ancorando-se na in-
2 Isabella Nardoni tinha cinco anos quando foi jogada da janela de um apartamento no sexto andar, em um prédio localizado em uma região de classe média alta, em São Paulo, em 2008. A primeira versão era de que haveria um ladrão no prédio. Vizinhos gravaram os primeiros momentos de comoção em torno da menina, encontrada com vida no gramado do prédio, e a chegada de familiares. Com a morte da menina e a suspeita do envolvimento do pai e da madrasta no crime, as investigações passaram a ser acompanhadas por um amplo volume de mídia, curiosos e protestos. Esta intensa atividade culminou-se com a transmissão, ao vivo, da reconstituição do crime, mas teve prosseguimento com depoimentos, transferências de presídio. O caso retornou com força durante o julgamento dos acusados, que foram condenados pelo crime, em 2010.

\footnotetext{
${ }^{3}$ Bernardo Boldrini foi morto aos 11 anos, em abril de 2014, com uma injeção letal, e o corpo da criança foi enterrado em uma cova feita previamente ao assassinato, em Frederico Westphalen, Rio Grande do Sul. A madrasta e uma amiga confessaram o crime e foram condenadas, juntamente com o pai da criança. Durante as investigações policiais, descobriuse que o menino tinha restrição de acesso à moradia, ficando muito tempo na casa de conhecidos. O próprio menino já havia procurado o Fórum para reclamar de abandono. Atormentados com estas informações de abandono, moradores de Frederico Westphalen organizaram missas, vigílias e protestos. Em 2015, peritos declararam que também a mãe de Bernardo, morta em 2010, não tinha escrito a suposta carta em que anunciava o suicídio, sendo também este caso reaberto.
} 

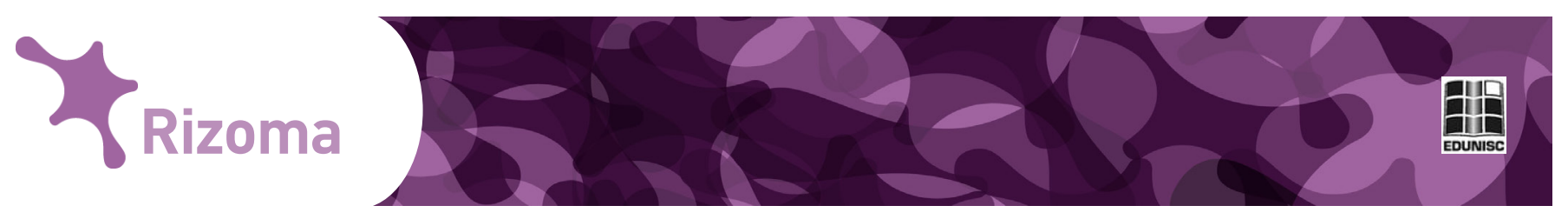

formação e transmissão direta. Junto a isso, ocorre a ascensão do entretenimento como linguagem que transborda toda a produção televisiva (GOMES, 2011) e que se torna a característica de um tempo e cultura midiáticos. Os espaços imaginários formados a partir das experimentações do audiovisual de grande público passaram a ser lugar da produção dos acontecimentos, de administração e negociação no "real" social (VERÓN, 2001).

Com a penetração do audiovisual, as formas de contato, que antes pertenciam ao cotidiano imediato, passam a ser articuladas em dinâmicas midiáticas, sendo o discurso impregnado pela técnica. Esta lógica promove a "ascendência de uma determinada realidade, que se expande e se interioriza sobre a própria experiência humana" (FAUSTO NETO, 2009), num ambiente técno-interacional. As características de meditatização da experiência são fortemente desenvolvidas com as tecnologias que possibilitaram que a internet se popularizasse como espaço interativo, de troca, conversa e produção de conteúdos - característica que esteve na base do que se denominou internet participativa ou colaborativa, a partir dos anos 2000.

Com esta base de troca e produção coletiva de conteúdos, amplia-se a tendência de se encontrar por aproximação de interesse mais que fisicamente, o que, na perspectiva de Vieira (2008), aprimora a realização de debates sobre assuntos comumente vividos pelos membros do grupo, possibilita a construção textual coletiva e expõe disputas e relações que têm em conta reputação e confiabilidade (CHRISTOFOLETTI, 2007). Em razão da proximidade promovida pelos interesses em comum e trocas de experiências, há uma ênfase ao tipo de relação de confiança estabelecida entre quem lê e quem oferta conteúdo. Há um deslocamento, portanto, no espaço de articulação dos conteúdos da realidade, com consequente afetação sobre as relações intencionais, voltadas ao espaço público e desenvolvidas a partir da linguagem, visando uma pauta ou objetivo - lugar que durante os séculos XIX e XX foi centrado no campo do jornalismo. Com a diversificação da produção, multiplicam-se ações fragmentadas, sem unicidade aparente, que podem vir de qualquer canto, que desafiam as instituições socialmente reconhecidas em processo que André Lemos caracteriza como a "abertura da emissão" (LEMOS, 2005).

Mas tal produção generalizada de conteúdos afeta todos os aspectos da vida ordinária dos indivíduos, destacando-se a característica da vigilância ou da exposição da intimidade (VIZER; CARVALHO, 2013). Além disso, há uma transformação na caracterização dos sujeitos dos processos comunicativos. Vizer e Carvalho (2014, p.45) analisam que não é óbvio pensar em um "sujeito central" em processos conformados por "sinais, imagens, dados e relatos construídos pela cultura tecnológica", diferentemente da lógica da construção do sujeito que se opera nos sistemas mediáticos e infocomunicacionais, centrado na figura do "indivíduo, grupo, públicos políticos ou mercados privados". Os autores aderem à noção de "ecologia da mídia”, em que há um "inter-jogo" entre máquinas e seres humanos, uma vez que cruzam-se intenções de atores como indivíduos ou instituições e as capacidades da máquina. 

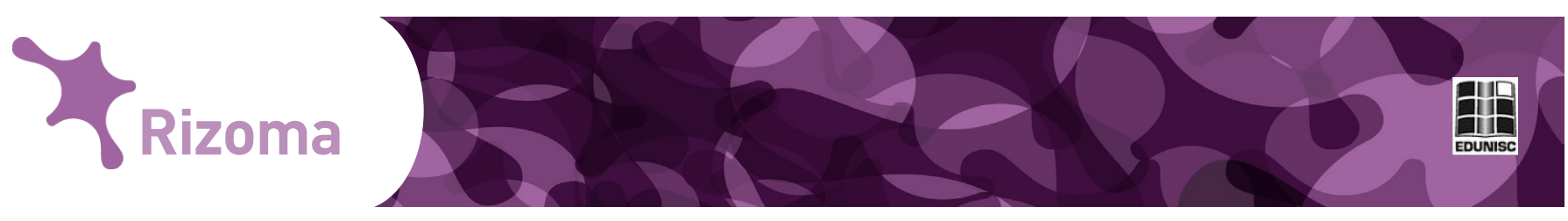

A complexidade da relação entre mídias, tecnologias, objetos, indivíduos e instituições também está presente em análise de Castells (2013) sobre os protestos pelo mundo, no ano de 2011. Castells avalia que o tensionamento às instituições está relacionado a um amadurecimento na vivência social destas instituições (o que propicia que sejam questionadas), a um aprendizado social midiático, que decorre dos séculos em que se desenvolve a midiatização do social a um esgotamento do modelo de organização da vida. Um componente particular está relacionado à lógica do que se sente: a "superação do medo", pela ideia de superar as condições objetivas de problemas e humilhações, da qual emergem sentimentos que "estimularam protestos espontâneos", iniciados por "jovens usando suas redes, as redes em que eles vivem e se expressam", das redes sociais na internet às redes pessoais (CASTELLS, 2013, p. 29).

Nos casos, aqui, estudados, analisamos aspectos de mediatização relacionados à aprendizagem associada à mídia, à apropriação tecnológica, à reconfiguração de conteúdos e à projeção de uma posição ao espaço público sobre os temas abordados na forma de vídeos, que desenvolvem a emoção pela lógica do amparo e da homenagem e projetam posições ao espaço público pela preocupação com a comoção, com a situação da infância e os dramas vividos pelos outros.

\section{A compaixão e a projeção do outro em circuitos comunicacionais}

A lógica da compaixão, na perspectiva de Paulo Vaz, é pensada em relação à igualdade, tendo em conta os lugares ocupados por quem pode ser objeto de compaixão - ou a quem se oferece solidariedade. Historicamente, em sociedades sem a universalização da moral, a solidariedade tinha a ver com o laço comunitário (quem pertence ao grupo) e era obrigação de pessoas específicas. Por outro lado, mesmo sociedades com regras universais, como os gregos, não tinham, necessariamente, a obrigação de solidariedade ao desconhecido (por exemplo, a aceitação da escravidão para uns dá a entender que se concebe um sofrimento "inevitável ou merecido").

No cristianismo, quebra-se a diferença e todos devem ser solidários com o sofrimento do estranho, mas não é feita a relação entre sofrimento e causa social. Paulo Vaz toma a análise de Hannah Arendt para afirmar que a revolução francesa, ao tornar o sofrimento de estranhos como espetáculo, parte deste reconhecimento para a necessidade de uma ação política, que possa reduzir ou eliminar o sofrimento. Com isso, admite-se que o sofrimento não depende da moralidade ou imoralidade do que sofre ou de uma forma de merecimento.

Nesta lógica de pensamento, a retórica do sofrimento, em casos midiáticos, se baseia na piedade. Há o sofredor, o responsável pelo sofrimento e o observador. A retórica se volta ao observador, que "pode fazer alguma 
coisa a respeito" (VAZ, 2014, p. 5). Assim, "além de se compadecer, se enternecer e se indignar", a audiência "deve agir politicamente". Nos séculos XIX e XX, como alguns que não sofrem se beneficiariam dos que sofrem, estes estão em dívida com os sofredores. Os sofredores são considerados não em sua singularidade, mas naquilo que carregam de uma condição partilhada por muitos. A esquerda passa a pautar a questão de que a hierarquia social determina condição de sofrimento para muitos e deveria ser destruída, para suprimir as condições culturais de produção do sofrimento. Este sofrimento deveria ser dado a ver, para que seu desconhecimento não produzisse a indiferença. Paulo Vaz identifica mudanças de valores que, transformando a concepção de sofrimento, gradualmente, mudam também a retórica:

Cada vez mais, acredita-se que o melhor é que o próprio sofredor se represente para a audiência, pois ninguém pode falar em seu nome e só pode falar de uma condição quem passou por ela. Desde quando surgiu a Internet, esse dispositivo técnico que permite a qualquer um tornar-se emissor, a recusa da distância entre representante e representado, entre, no caso, observador e sofredor, permitiu a explosão dos relatos autobiográficos na forma testemunhal. Essa autoridade da experiência provoca ainda a ascendência de novos critérios de verdade na narrativa jornalística, principalmente estar próximo do evento e ter corrido risco pela proximidade (VAZ, 2014, p. 9).

Aumenta-se a preocupação com a emoção, em lógica que também participa da fabricação midiática. Análises e proposições teóricas recentes consideram a TV como algo a mais que uma teia de conteúdos informativos, mas que envolve emoções (WILLIANS, 2003), contato e indicialidade (VERÓN), circularidade autorreferencial (FAUSTO NETO, 2009), sensação de presença (FECHINE, 2006), entretenimento como linguagem (GOMES, 2011). Tais aspectos tratam de assuntos que têm em vista o espaço público, mas são organizados a partir de lógicas envolvendo sensações e emoção. De modo similar, tais aspectos marcam a produção dispersa de conteúdos por pessoas que não estão vinculadas a segmentos profissionais das indústrias midiáticas, mas que se apropriaram da vivência midiática, do aprendizado tecnológico e da disponibilidade de recursos e redes para espalhar conteúdos e desenvolver sua produção. Nestes casos, a reapresentação do sofrimento ocorre pela visitação a detalhes da intimidade, a partir de vídeos domésticos e fotos de dia a dia, no caso Isabella, e de vídeos e fotos de pessoas que conheceram e conviveram em ambientes diversos com Bernardo. Com a renúncia de vínculo com a família do pai de Bernardo, a produção de conteúdo recorre aos colegas de escola, de igreja e de bairro que dividiram algum momento com o menino. $\mathrm{O}$ sofrimento é apresentado por outros, mas de forma a recompor as lógicas da intimidade das crianças e sua experiência única. 

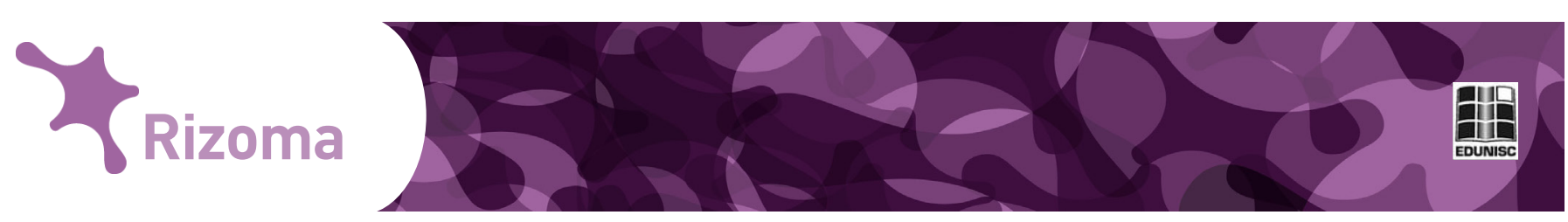

\section{Caso Isabella em vídeos de homenagem: a celebração de marcos de vida e morte}

Os vídeos de homenagem feitos em memória de Isabella demonstram a realização de pesquisas de vídeos e imagens, misturando coisas encontradas no arquivo pessoal da mãe da menina (disponíveis, à época do assassinato, no Orkut), imagens reproduzidas midiaticamente, outras produzidas como parte da cobertura do acontecimento. Algumas destas imagens e vídeos são retrabalhados por pessoas fora do campo midiático empresarial e igualmente não pertencentes ao circuito da vida familiar da menina.

Um dos vídeos de homenagem à Isabella, publicado no Youtube, aparece em segundo lugar na busca orgânica do Google (a busca que não relaciona anúncios). Utilizando este link, encontramos outros vídeos de homenagem à Isabella, na lista de materiais relacionados. Em alguns vídeos, a parte destinada à descrição é usada também para enfatizar a ausência de parentesco entre a pessoa que posta o vídeo e a menina. Há usuários que postam vários vídeos em homenagem à menina e à mãe, caracterizando uma preocupação recorrente com o caso e possivelmente com interesses das pessoas que recebem seu conteúdo.

A midiatização intensa do caso Isabella resultou em índices elevados de visualização dos materiais a ela relacionados. O vídeo que aparece em destaque no sistema de busca tinha mais de 16 milhões de visualizações em julho de 2014 (tendo sido supostamente visto todas estas vezes).

Figura 1: Vídeo conta com milhões de visualizações

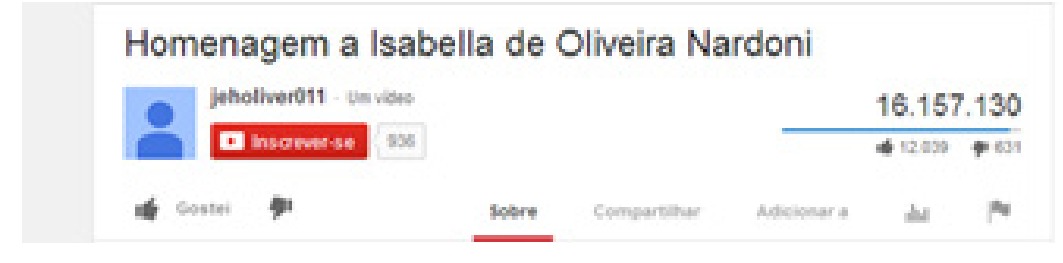

Os vídeos de homenagem encontrados têm uma estrutura similar: uma seleção de fotos que recompõe fatos, lugares, eventos, momentos da intimidade de Isabella. Em muitas das fotos, Isabella aparece acompanhada pela mãe, cuja presença no circuito midiático é intenso durante toda a investigação de assassinato. Alguns vídeos surpreendem pela utilização de arquivos de fotos de Isabella bebê, não tão comuns em circuitos jornalísticos à época de sua morte. A quantidade de imagens permite observar uma pesquisa de dados intensa pela pessoa que organizou o material. 

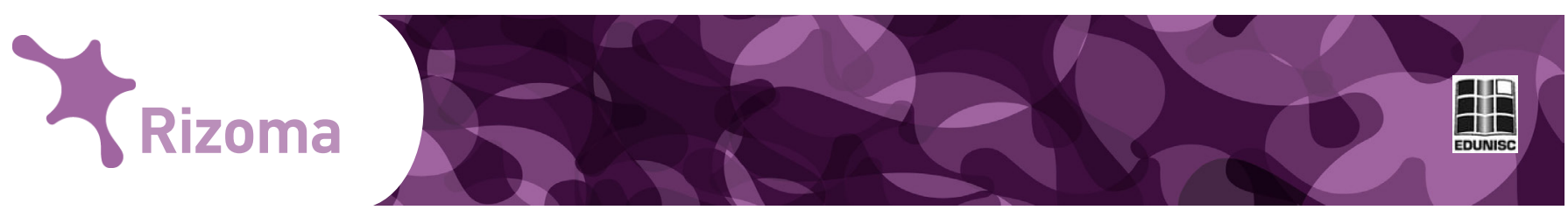

Figura 2: Fotos de arquivo pessoal reutilizadas para vídeos de homenagens
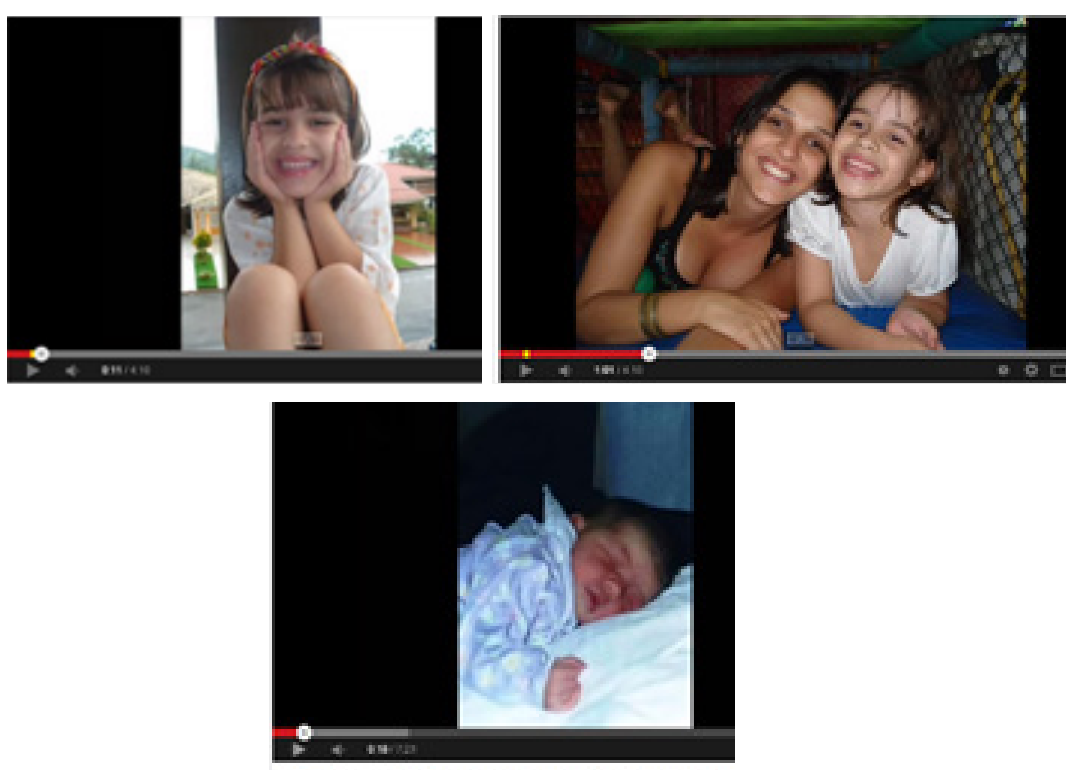

Homenagem Otcial a lsabela de Otvera Nardoni - .

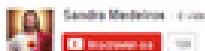

Algumas estratégias de edição apresentam-se desde a escolha dos materiais de arquivo, como vídeos que relacionam fotos do enterro de Isabella, fotografias da mãe, chorando, com a camiseta da menina. Este tipo de produção recupera a noção do sofrimento materno associado ao acontecimento. Esta relação é constituída em oposição à noção da felicidade partilhada por mãe e filha em todos os eventos cujos registros fotográficos fazem parte dos recortes operados para os vídeos. A seleção de imagens segue critérios de qualidade de imagem, escolha de planos, de cenas que tecem uma lógica narrativa. Os títulos, descrições e data da publicação mostram a ligação do vídeo com eventos como aniversário, morte, julgamento dos acusados.

Figura 3: Fotos de vídeos em memória de dadas e enquadramento de Ana Carolina, em tomada com símbolo da emissora, chorando

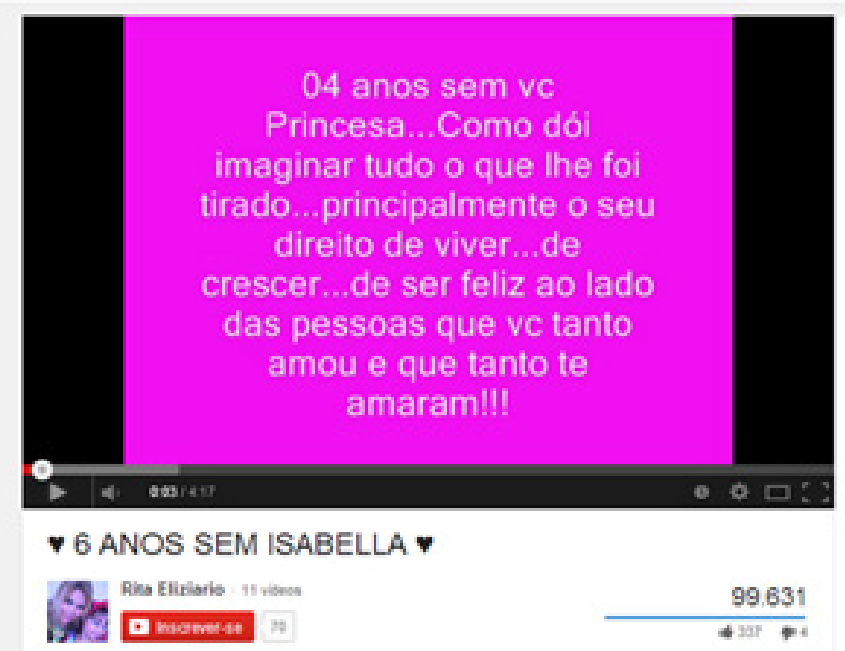

Rizoma, Santa Cruz do Sul, v. 3, n. 1, p. 70, julho, 2015 

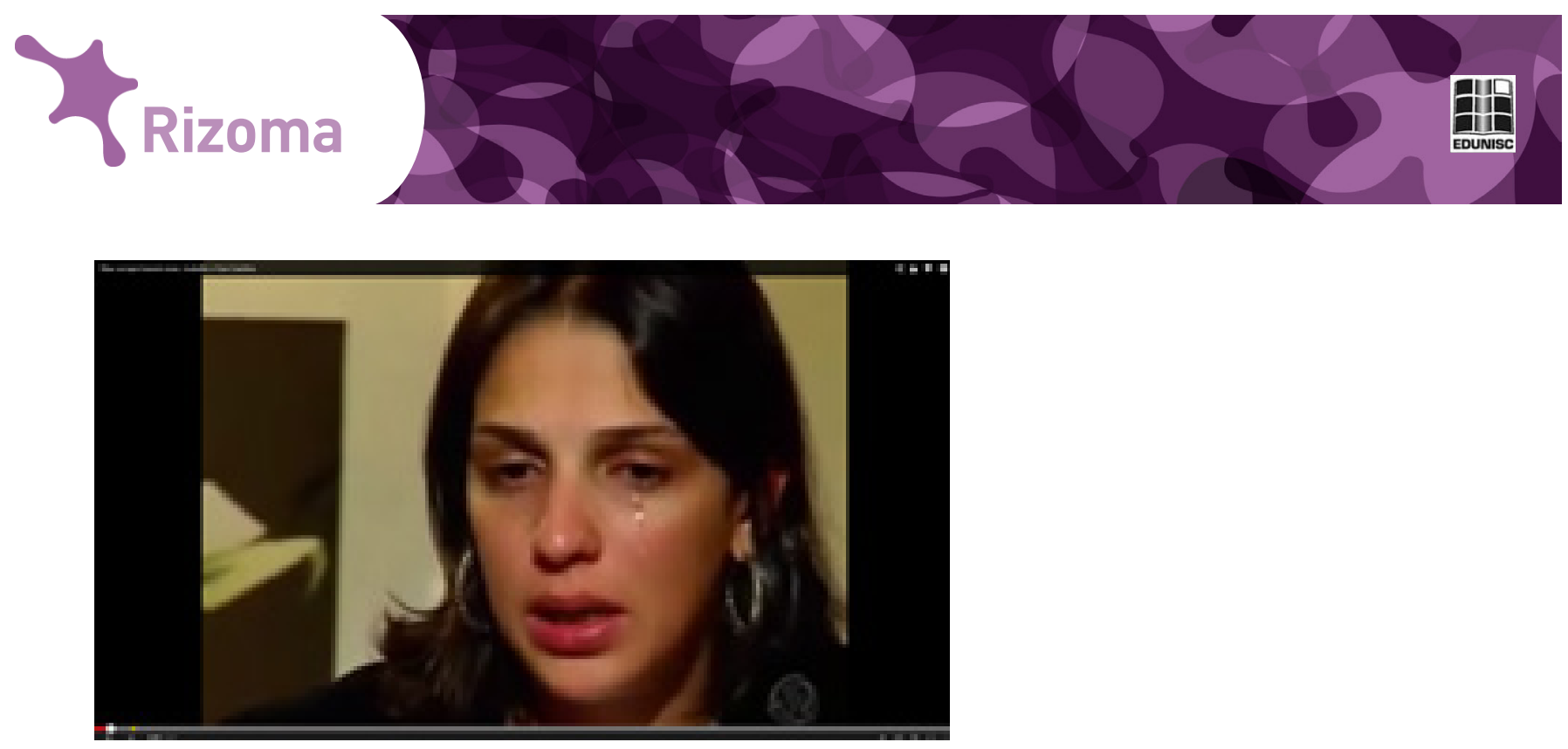

Observa-se que ocorre um trabalho de produção sobre o tipo de narrativa organizada. Há prevalência para o sorriso da menina, ênfase na musicalização e até utilização de mensagens, apresentando-se algumas estratégias de pós-edição deste material. Destacam-se utilização de bordas, sobreposição de imagens e associação entre texto e imagens.

Figura 4: Procedimentos de edição de vídeo
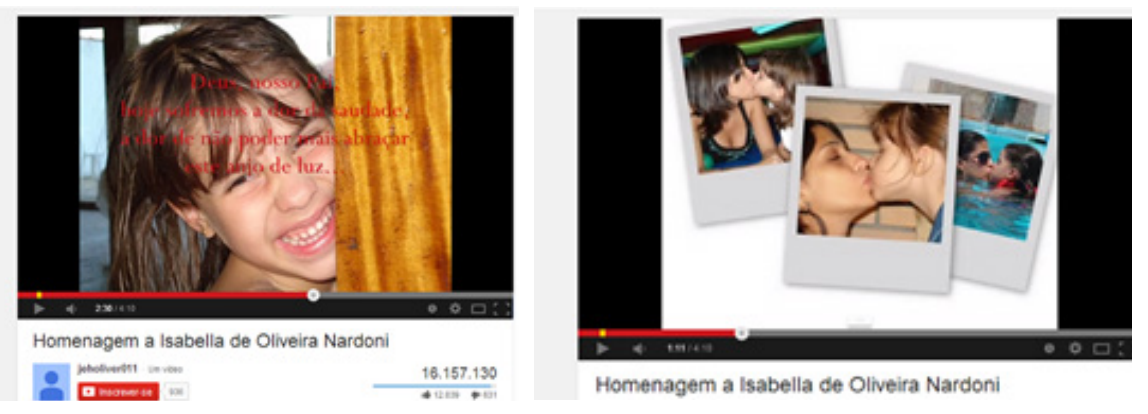

Os vídeos são frequentemente acompanhados por uma trilha sonora que, em geral, é associada à produção musical religiosa. "Resolvi pedir a Deus para que eu possa te guardar”. Em algumas descrições, os próprios usuários relacionam a letra da música com as fotos e o modo como interpretam o caso. Há vários vídeos que destacam a relação mãe e filha: “eu fiz esse vídeo em homenagem a ela, agradecendo por ela ter gerado, protegido e amado a sua filha Isabella. A canção diz o seguinte: 'Obrigado por me amar, por ser meus olhos quando eu não podia ver"'. Há vídeos que mostram a ocorrência de composição de músicas, com o objetivo de refletir sobre as características do caso e homenagear a menina Isabella.

A marca da gravação feita a partir das transmissões televisivas aparece em algumas cenas escolhidas. Há um híbrido entre material jornalístico, fotos, música e comentários feitos pelos próprios usuários. Esta característica reaparece em gravações feitas por pessoas no âmbito do desenvolvimento de suas atividades sociais, quando dedicam espaço ao caso Isabella, incluindo missas e participação em programas televisivos, com apresentação de músicas feitas para a Isabella. 

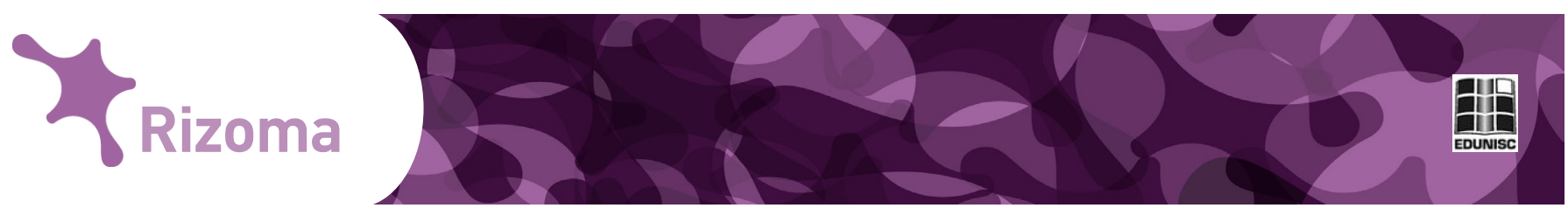

Figura 5 Missa em homenagem à Isabella Nardoni, à esquerda, e menina cantando música para Ana Carolina Oliveira (a mãe), em programa de TV, à direita
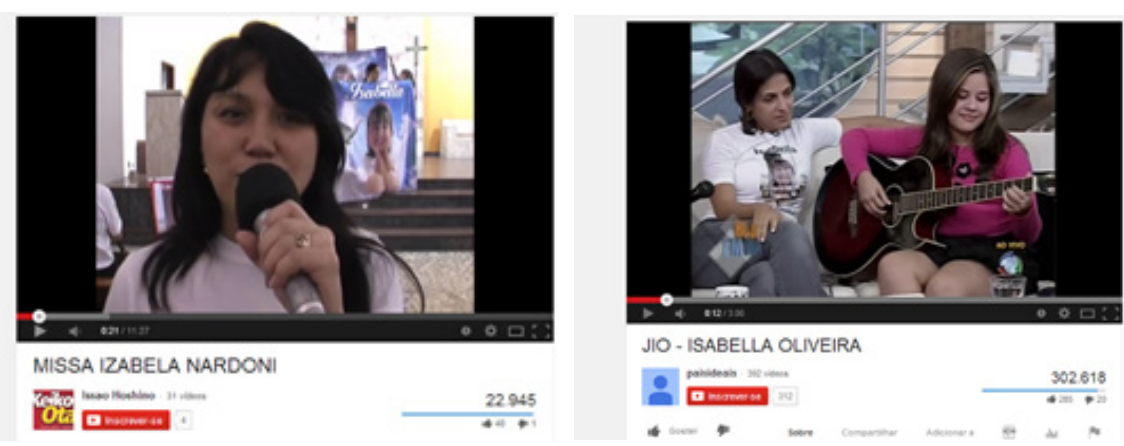

Há missas e programas religiosos postados na internet e pessoas que fizeram vídeos em homenagem a menina são chamados à televisão, sendo os vídeos parte de uma re-circulação no YouTube.

As estratégias de posicionamento no espaço público permitem evidenciarmos as características de mediatização incidindo sobre as interações com as narrativas do cotidiano, sendo possível identificar uma ampla difusão das técnicas discursivas do jornalismo e do campo do entretenimento, garantindo um retorno à mídia (FAUSTO NETO, 2008). Observa-se ainda a operacionalização instrumental que permite a seleção de conteúdos, a edição, a montagem e a inserção de conteúdos próprios (LEMOS, 2005). A possibilidade de combinar informações e gerar conteúdos diferentes também passa por aspectos da mediatização dos campos sociais, sobretudo o religioso, pela associação a espaços e falas/cantos religiosos próprias destes campos. Tais associações vinculam-se ainda com a experimentação de talentos próprios, que possibilitam ativar os fluxos de redes e motivar a abertura de circuitos comunicacionais (BRAGA, 2006).

\section{Caso Bernardo em vídeos de homenagem: culpa, consolo e indignação}

Os vídeos feitos em homenagem ao menino Bernardo Boldrini, assassinado em abril de 2014, seguem características comuns ao tipo de formato apresentado dos vídeos feitos em homenagem à Isabella, com músicas religiosas e fotos acompanhadas por mensagens ${ }^{4}$. Estas mensagens diferem-se da centralidade ao amor materno, e agregam a busca de cuidado empreendida pelo menino como exercício reflexivo central.

$\mathrm{O}$ vídio intitulado "In memoriam do pequeno Bernardo Uglion Boldrini" combina mensagens escritas sobre fotos e citações que refletem sobre o caso e também referem-se sobre o amor concedido via memória, como resposta ao abandono: "apenas queria ser amado, dando uma chance para seu "pai"; "A gente não esquece. O que a memória ama, fica eterno". O vídeo se direciona diretamente ao debate público, usando uma imagem da bandeira nacional com a frase: “acorda, Brasil!". Este vídeo também aciona aspectos relacionados a outros sites de redes sociais, como o pôster convidando para a troca da foto de perfil por uma foto de Bernardo, utilizando a hashtag \#corrente_do_BEm.
${ }^{4}$ Bernardo foi morto com uma injeção letal e o corpo enterrado em uma cova em Frederico Westphalen, no norte do Rio Grande do Sul. Nesta data, foram presas a madrasta e uma amiga, que confessaram o crime. O pai, Leandro Boldrini, a madrasta, Graciele Ugulini, e uma amiga dela, Edelvania Wirganovicz, estão presos. Durante as investigações, descobriu-se que o menino tina restrição de acesso à moradia, ficando muito tempo na casa de conhecidos. O próprio menino, aos onze anos, procurou o Fórum para reclamar de abandono. Uma tentativa de reconciliação com o pai foi procurada. A nova audiência estava marcada para poucos dias após a morte do menino. 

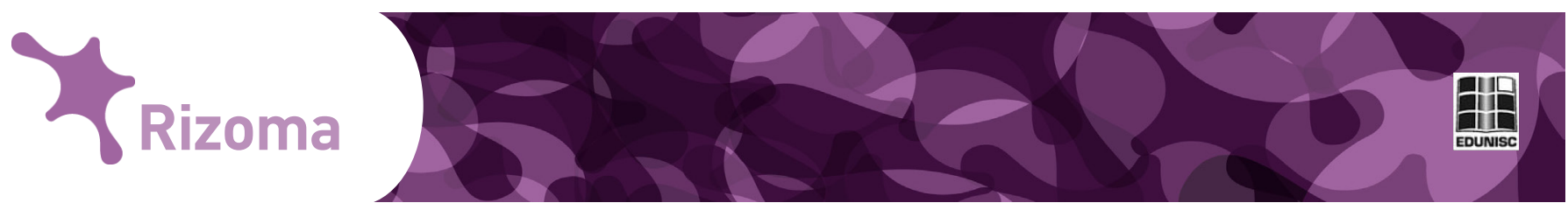

Figura 6: Conclamação à ação pública em redes sociais
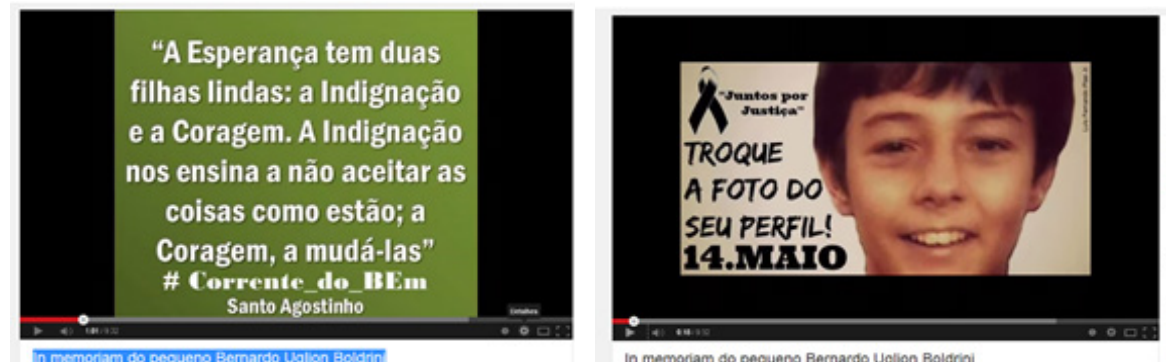

O posicionamento com relação ao debate público mostra-se claramente vinculado ao jornalismo em outro vídeo homenagem, que inicia com imagens das manchetes jornalísticas sobre o caso.

Figura 7: Chamamento ao debate através do jornalismo e diretamente à sociedade
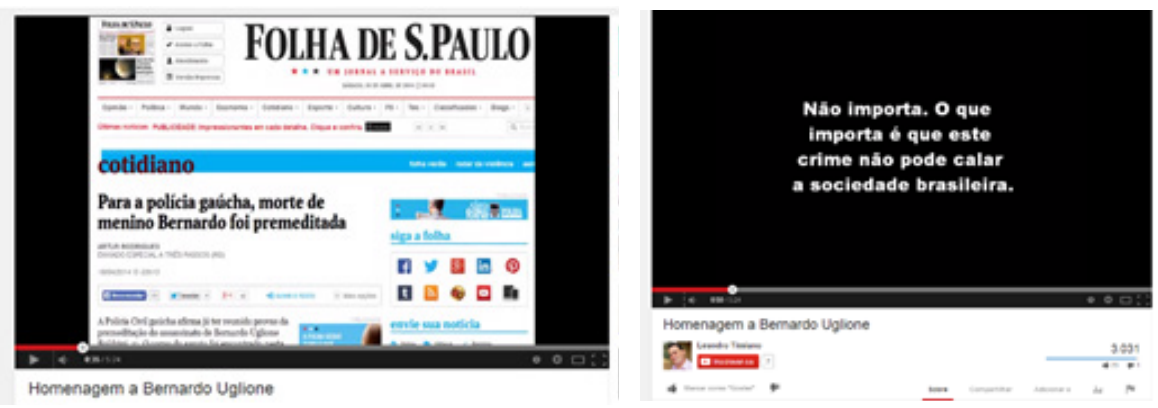

Um destes vídeos de homenagem foi utilizado como imagem documental por um canal jornalístico: nele, o menino mostrava um cartaz com o nome da madrasta. O cartaz havia sido utilizado em uma atividade da escola, em razão do dia das mães. A música do clipe diz: "mãe, me dá teu colo, mãe!". A escola e pessoas a ela vinculadas fornecem vídeos para emissoras de televisão, e estes materiais voltam a circular em canais alternativos, vinculados a pessoas externas ao campo do jornalismo.

Figura 8: Vídeo divulgado por escola, reproduzido em redes sociais e transmitido em emissoras de TV, para circular outra vez no YouTube

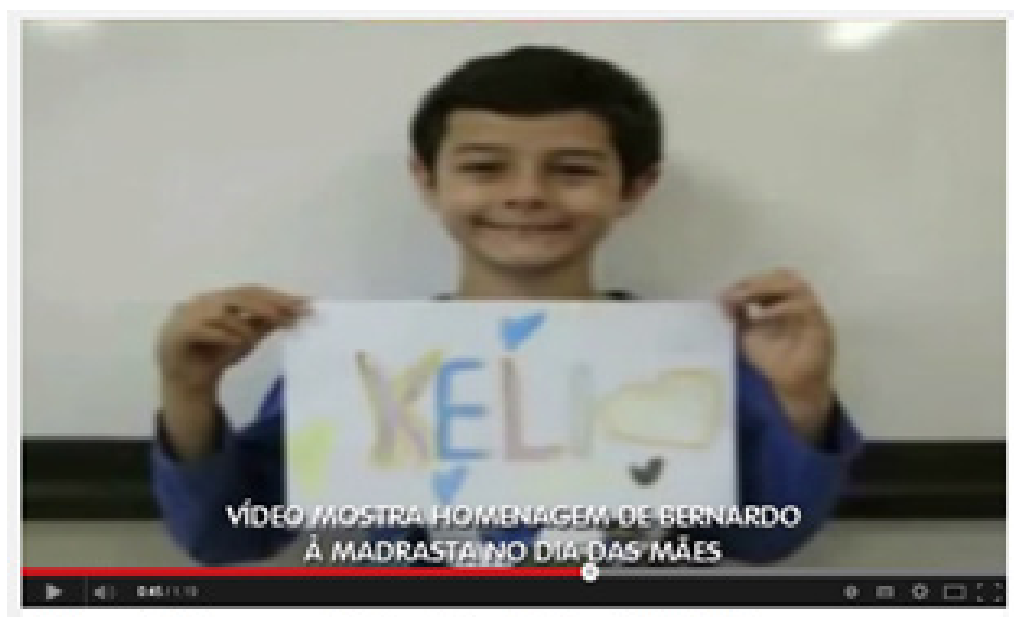



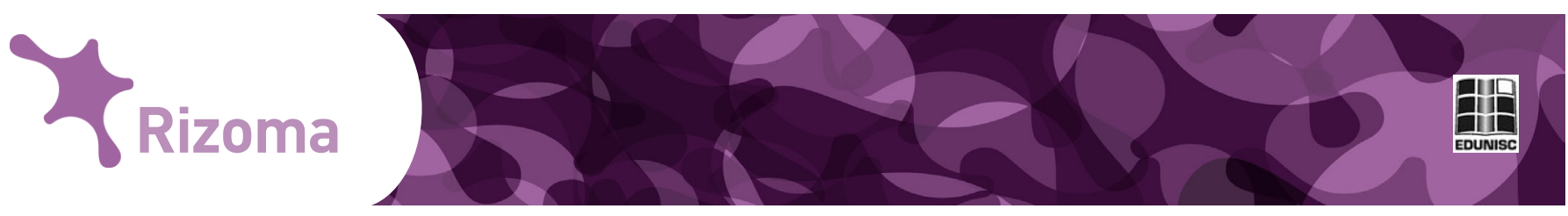

A comoção com a descoberta das condições em que a criança estava vivendo está presente na escolha das músicas que acompanham os clipes. "Eu não tenho mais medo" ", diz a letra de clipe que combina imagens de colegas de escola expondo cartazes, com velas, pedindo justiça, fotos de arquivo pessoal (o menino com a mãe e a avó, não envolvidas no crime, vestindo camiseta de clube de futebol, na sala de aula, nadando, em quase todas sorrindo). São também reforçadas as presenças de pessoas da comunidade que tiveram presença efetiva na vida do menino. Além dos vídeos e fotos da escola, é recorrente a foto da primeira comunhão do menino, que foi acompanhada por um casal da Igreja - e não pelo pai.
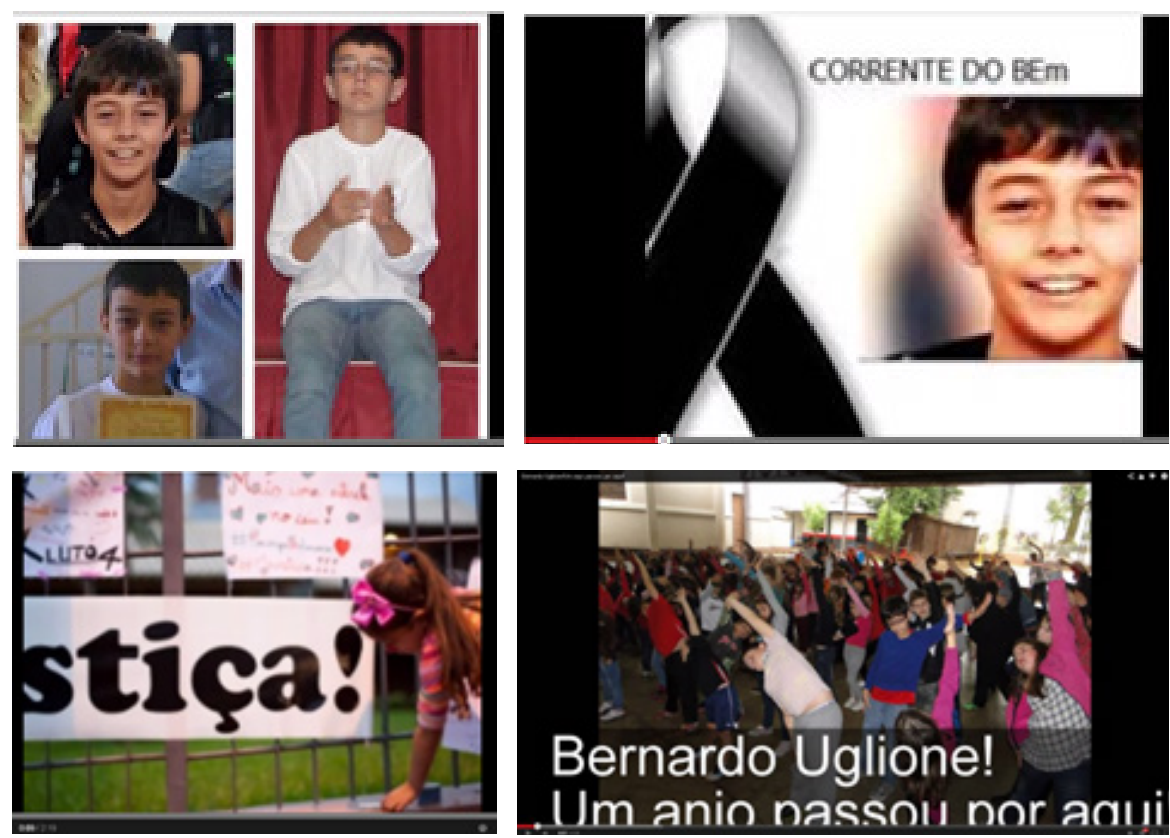

Também entre os vídeos em homenagem a Bernardo são combinadas fotografias do menino com falas e exposições realizadas em sua memória. É o caso da sonora de um texto, acompanhado por músicas e imagens (no espaço de descrição do vídeo o texto está completo), e de um vídeo gravado em uma missa realizada em homenagem ao menino. Em vídeo que mostra multidão rezando e cantando em frente à casa em que Bernardo vivia, a letra da música também fala de dor e sofrimento: "Deus te trouxe aqui para aliviar o seu sofrimento; O mundo pode até fazer você chorar, mas Deus te quer sorrindo" ${ }^{6}$.
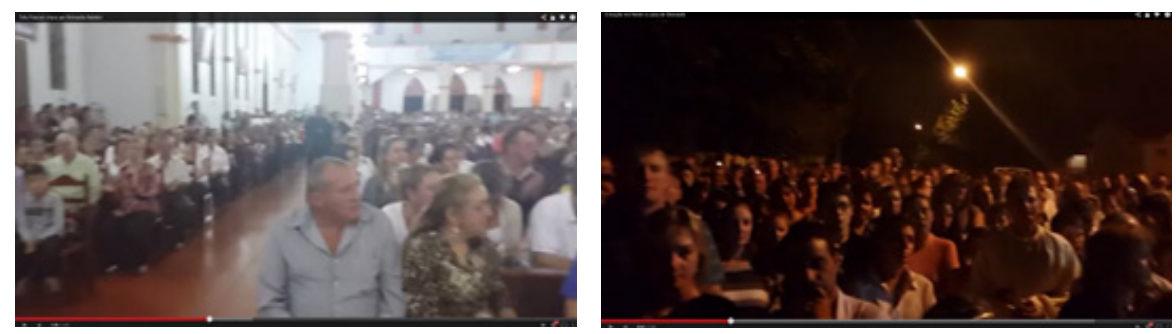

Diferentemente dos vídeos em homenagem a Isabella, os vídeos em ho-
5 Traduzido do trecho: I am not afraid anymore", da música I Wouldn't Mind.

6 "Noites traiçoeiras", de Simone Telésforo. 

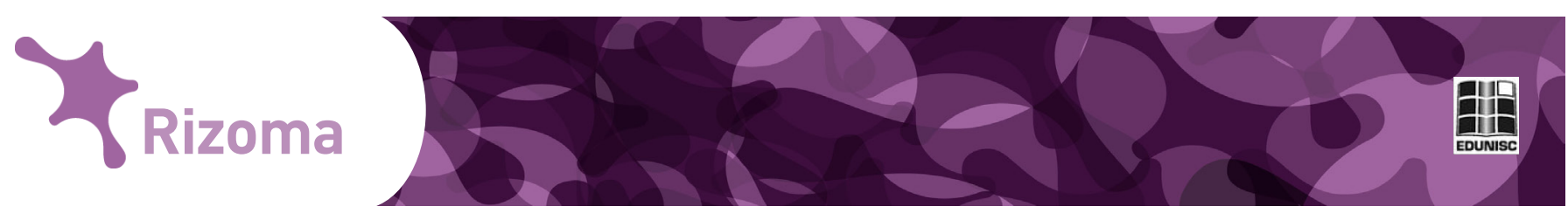

menagem a Bernardo contêm um maior número de fotos do menino junto com outras crianças, tiradas na escola e na igreja no dia da Primeira Comunhão. Estas fotos prevalecem em comparação com o número de fotos do menino com a família - quando a família aparece, a exemplo do que acontece com as homenagens para Isabella, as fotos privilegiam a mãe, e agregam, em decorrência do fato de a mãe ser falecida, a avó materna, constantemente entrevistada durante as investigações do homicídio. Esta prevalência promove o silenciamento das figuras responsáveis pela morte do menino, que não ganham espaço no vídeo.

No caso de Bernardo, a presença superior de fotos em ambientes públicos reforça a comoção com as informações que assinalavam abandono da figura paterna, sendo a criança órfã de mãe. Esta fala é repetida em textos lidos em homenagem ao menino. "Seremos sempre para você uma família que te ama, que sente a tua falta, que sabe que agora você está junto de Deus", diz texto lido em celebração na Igreja da qual ele participava.

\section{Considerações finais}

O jornalismo participa destas (re)criações audiovisuais, sendo fonte de considerável parte dos recursos imagéticos e informativos. Podemos pensar em características importantes da relação das pessoas com a mídia, analisando uma aceleração da midiatização, cujas afetações múltiplas, dispersas e totalizantes podem ser percebidas na sociabilidade contemporânea, espalhadas em circuitos midiáticos-interativos, de entretenimento, de relacionamento e de informação. Estas características são perceptíveis pela interlocução com o espaço público via publicação de conteúdos fora do circuito midiático.

A repetição entre os conteúdos midiáticos, observada por Ignacio Ramonet nos anos 1990, está presente neste tipo de filtragem e reorganização de materiais pelas pessoas fora do circuito industrial, no Youtube. Os circuitos comunicacionais informativos, que já estavam expandidos, proporcionando que todas as instituições mais ou menos organizadas elaborassem estratégias de direcionamento ao público, são acionados por diversas pessoas, com as plataformas de publicação de conteúdos na internet.

Assim como as instituições, empresas e grupos tentavam influenciar o debate público via estímulo à comunicação (RAMONET, 1995), indivíduos ou pequenos grupos também buscam esta forma de participação. Se neste contexto, o controle do que se tornava notícia e a medição de audiências de programas televisivos permitiam a conformação de correntes de opinião, pressionando por ações políticas, esta dimensão se espalha a este tipo de iniciativa de criação de materiais, divulgação de conteúdos, reaproveitamento dos produtos jornalísticos.

Paulo Vaz (2014) analisa que, em coberturas midiáticas de tragédias, são acionadas noções de felicidade e sofrimento em relação aos papéis sociais que definem o que pauta as ações de solidariedade. Na abordagem de tragédias, parece haver uma ênfase contemporânea às vítimas como pessoas 

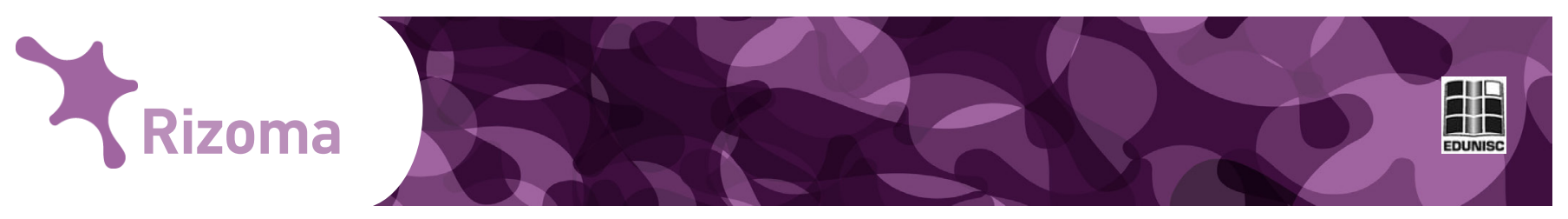

felizes, até o dia da tragédia. Este tipo de construção transcende às lógicas da produção midiática, participando da formulação de produtos tais como os vídeos de homenagem, que circulam em redes digitais.

Observamos que estes vídeos posicionam-se na construção de um campo temático que reflete sobre a preservação da infância, pela comoção com o sofrimento (1) da mãe que perde a filha e da vida feliz interrompida, de Isabella, e (2) da comoção pelo conhecimento público da condição de sofrimento em vida, de Bernardo. No caso das homenagens à Isabella, as fotos remetem aos bons momentos da menina com a mãe, quase sempre sorrindo. Nos vídeos em homenagem a Bernardo, a um tom de culpa coletiva pelo sofrimento da vítima em vida - ou a ausência da felicidade. Embora, em algumas fotos apareça sorrindo, em outras há uma aparição discreta, em meio a outras crianças. Em ambos os casos, os materiais se dirigem a esta nova composição do espaço público, buscando a comoção e envolvimento em questões sociais sobre a morte das crianças. Aqui, como nos casos analisados por Paulo Vaz, há a ausência do criminoso como polo de referência informativa.

Os sistemas de comunicação e informação, nos casos abordados, atuavam de forma coordenada para corroborar para uma intercompreensão, a partir da promoção de ações comuns entre os media e os membros de um grupo, visando a realizar seus objetivos, apresentar suas opiniões, reagir diante das opiniões alheias (CORREIA, 1998). Passava por esta noção de campo midiático, portanto, a própria articulação do espaço público, visando "a qualidade do relacionamento dos seus membros" (CORREIA, 1998, p. 8), a partir de características de acesso à ação e à discussão.

Quando observamos a dispersão na produção de conteúdo, com suas características de recombinação e montagem, que fazem diluir-se elementos como "autoria" sobre as imagens, de "propriedade" sobre o conteúdo, vemos igualmente a dispersão do tipo de relação com a construção de um público. Embora isso, vemos manifestarem-se aspectos que claramente tensionam a produção de sentidos sobre um campo temático de importância central para as sociedades modernas, a infância, o que se faz a partir da apropriação de discursos e estratégias midiáticas e da experimentação coletiva, envolvendo modos de modificação de conteúdo e circulação.

\section{Referências}

BRAGA, José Luiz. Sobre "mediatização" como processo interacional de referência. 15 encontro anual da Compós - Associação Nacional dos Programas de Pós-Gradação em Comunicação. UNESP - Bauru, 6-9 de junho de 2006.

Dispositivos interacionais. Trabalho apresentado ao Grupo de Trabalho Epistemologia da Comunicação, do XX Encontro da Compós, na Universidade Federal do Rio Grande do Sul, Porto Alegre, de 14 a 17 de 

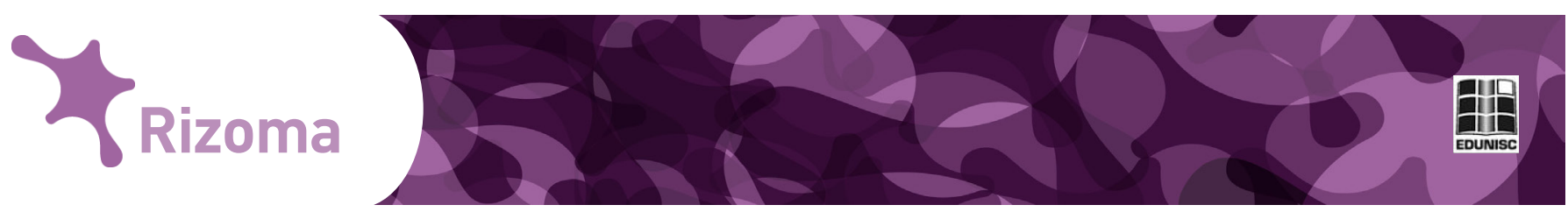

junho de 2011. 2011c.

CASTELLS, Manuel. Redes de indignação e esperança. Movimentos sociais na era da internet. Rio de Janeiro, Zahar, 2013.

CHARAUDEAU, Patrick. Discurso das mídias. São Paulo: Contexto, 2006.

CHRISTOFOLETTI, Rogério. Credibilidade jornalística e reputação na blogosfera: mudanças entre dois mundos. 2007. In: $5^{\circ}$ Encontro Nacional de Pesquisadores em Jornalismo, 2007, Aracaju. Anais do $5^{\circ}$ Encontro Nacional de Pesquisadores em Jornalisto. Aracaju: SBPJor, 2007.

CORREIA, João Carlos. O poder do jornalismo e a mediatização do espaço público. Revista de Comunicação e Linguagens. Lisboa: Universidade Nova de Lisboa, 2000. pp. 193-212.

Jornalismo e espaço público. Covilhã: Universidade da Beira do Interior, 1998.

FAUSTO NETO, Antônio. Fragmentos de uma "analítica" da midiatização. Matrizes, Vol. 1, No 2 abril 2008.

Jornalismo: sensibilidade e complexidade. Revista Galáxia,

São Paulo, n. 18, p.17-30, dez. 2009.

FECHINI, Yvana. Uma proposta de abordagem do sensível na TV. Trabalho apresentado ao Grupo de Trabalho "Produção de sentido nas mídias", do XV encontro da Compós, na Unesp, Baurú, SP, em junho de 2006.

GOMES, Itania Maria Mota. Gênero televisivo como categoria cultural. Revista Famecos. Porto Alegre, v. 18, n. 1, p. 111-130, jan./abr. 2011.

GROSSBERG, Lawrence. Let's tell a different story. Entrevista a LIANG, Island; WONG; Panger; WONG, Hoi-wing; CHAN, Shun-hing. Transcrição de Island Liang. June 2005. Disponível em <http://www.ln.edu.hk/mcsln/3rd_issue/pdf/interview01.pdf $>$. Acesso em junho de 2014.

GUNKEL, David. Audible Transgressions: Art and Aesthetics after the Mashup. In GUNKEL, David J; GOURNELOS, Ted. Transgression 2.0. Media, culture, and the politics of a digital age. Nova Iorque: Continuum, 2012 .

FECHINE, Yvana. Uma proposta de abordagem do sensível na TV. Trabalho apresentado ao grupo produção de sentido nas mídias, do XV Encontro da Compós, na Unesp, Bauru, SP, em junho de 2006.

KLEIN, Eloisa Joseane da Cunha. Circuitos comunicacionais ativados pela 

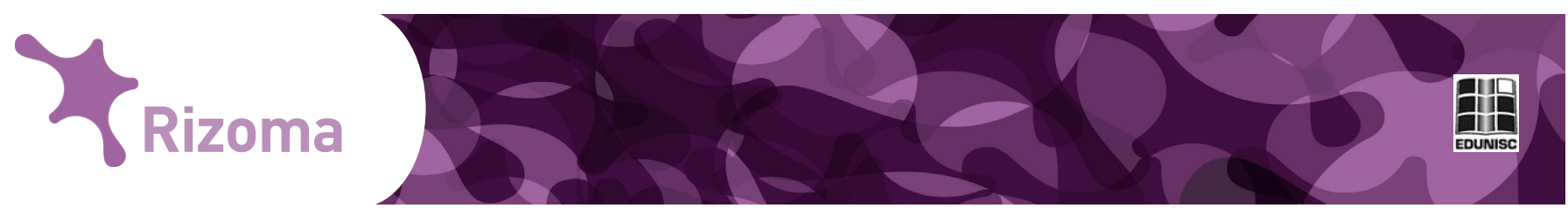

autorreferência didática no jornalismo: o caso do Profissão Repórter. Tese de doutoramento apresentada ao Programa de Pós-Graduação em Ciências da Comunicação da Unisinos. São Leopoldo: Unisinos, abril de 2012.

MORIGI, V. J. ; FLORIANI, Adriano Warken. Circuitos Comunicativos e a Construção da cidadania no ciberespaço: tramas do sentido em redes de weblogs. Revista Famecos (Impresso), Porto Alegre-RS, v. 30, n. 1, p. 107$114,2006$.

FRÓIS, Érica Silva; MOREIRA, Jacqueline de Oliveira. A imagem corporal da criança e as novidades do brincar pela internet: um ensaio teórico. Pesquisas e práticas psicossociais 5 (2). São José Del Rei, agosto/dezembro 2010.

LANDOWSKI, Eric. Presenças do outro: ensaios de sociossemiótica. Trad. Mary Amazonas Leite de Barros. São Paulo: Perspectiva, 2002

BURGESS, Jean. YouTube e a revolução digital: como o maior fenomeno da cultura participative transformou a mídia e a sociedade. Tradução Ricardo Giassetti. São Paulo: Aleph, 2009.

LEMOS, André. Cibercultura e Mobilidade. A Era da Conexã. Trabalho apresentado no XXVIII Congresso Brasileiro de Ciências da Comunicação - Uerj -5 a 9 de setembro de 2005.

LÉVY, Pierre. A inteligência coletiva: por uma antropologia do ciberespaço. 4.ed. São Paulo: Loyola.2003.

MARTÍN-BARBERO, Jesus. Dos meios às mediações. Tradução Ronald e Polito Sérgio Alcides. Rio de Janeiro: Editora UFRJ, 1997.

RAMONET, Ignacio. O Pensamento Único e os Novos Senhores do Mundo. São. Paulo: Publicações LCC Eletrônicas, 1995.

VAZ, Paulo. A compaixão, moderna e atual. Paper. Universidade Federal do Rio Grande do Norte. Natal, 2014.

VERÓN Eliseo. El cuerpo de las imágenes. Bogotá: Grupo Editorial Norma, 2001.

VIEIRA, Marli Fátima Vick. Ambiente Wiki na educação: Produção Colaborativa do Conhecimento Compartilhada na Web. Disponível em $<$ http:// tecnologiasnaeducacao.pro.br/revista/a1n1/art1.pdf $>$.

VIZER, Eduardo; CARVALHO, Helenice. La metáfora ecológica em la era de la mediatización. In RUBLESCKI, Anelise; BARICHELLO, Eugenia Mariano da Rocha. Ecologia da Mídia. Santa Maria: FACOS-UFSM, 2013. 

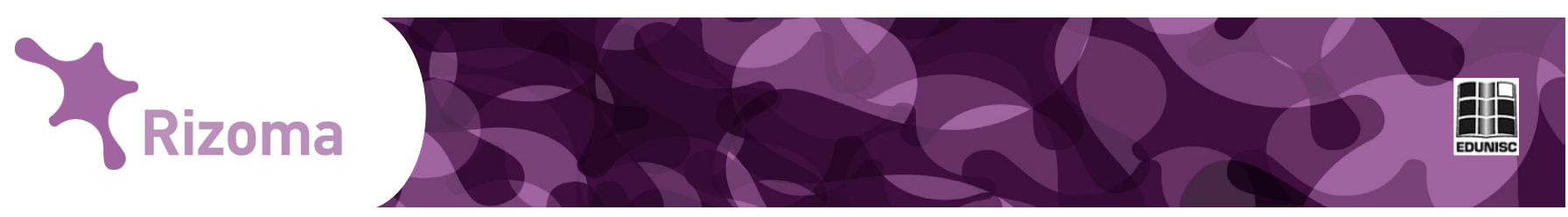

WILLIAMS, Raymond. Television. Technology and cultural form. London: Routledge, 2003.

\section{Vídeos com imagens e conteúdo citados:}

YOUTUBE. Seis anos sem Isabella. Disponível em: https://www.youtube. com/watch? $v=$ fzsnPz61YYc. Publicado em 22/03/2012. Consultado em julho de 2014.

YOUTUBE. Obrigado por me amar, mamãe. Uma homenagem a Isabella Nardoni e Ana Carolina de Oliveira. Disponível em: https://www.youtube. com/watch? $v=c$ RcyIorHBKg. Enviado em 23/02/2012. Consultado em julho de 2014.

YOUTUBE. Mas sempre haverá amor, Isabella e Ana Carolina. Disponível em: https://www.youtube.com/watch?v=d_X6aPVvFuY._Publicado em 07/12/2012. Consultado em julho de 2014.

YOUTUBE. Missa Isabella Nardoni. Disponível em: https://www.youtube. com/watch?v=hYG4farRIDo.Enviado em 08/04/2011. Consultado em julho de 2014.

YOUTUBE. Jio - Isabella Oliveira. Disponível em: https://www.youtube. com/watch?v=ycmQjcyFnag.Enviado em 30/03/2009. Consultado em julho de 2014.

YOUTUBE. Homenagem à Isabella - música original. Disponível em: https://www.youtube.com/watch?v=MY-OqsV4Clw. Enviado em 09/04/2009. Consultado em julho de 2014.

YOUTUBE. Homenagem à Isabella. Música amor de mãe e filha. Composição. Mairinha. Disponível em: https://www.youtube.com/watch?v=VKIzTxaDcXw. Enviado em 15/04/2008. Consultado em julho de 2014.

YOUTUBE. Cinco anos sem Isabella Nardoni, a minha infinita princesinha. Disponível em: https://www.youtube.com/watch?v=SaeqhAZnTwA. Publicado em 30/03/2013. Consultado em julho de 2014.

YOUTUBE. Vídeos mostram Bernardo fazendo homenagens a casal que o matou no Rio Grande do Sul. Disponível em: https://www.youtube.com/ watch?v=2Pk0czRy_pg.23/04/2014. Consultado em julho de 2014.

YOUTUBE. Homenagem a Bernardo Boldrini. Disponível em: https://www. youtube.com/watch? $\mathrm{v}=\mathrm{IeMZy3DWFdc.21/04/2014}$. Consultado em julho de 2014.

YOUTUBE. Bernardo Uglione!Um anjo passou por aqui! Disponível 

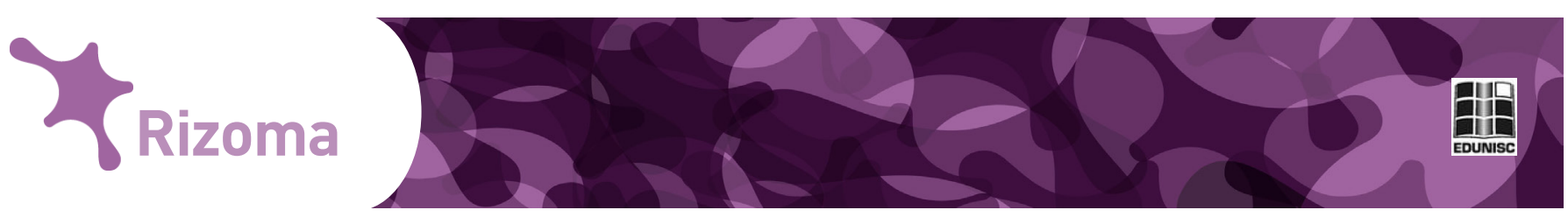

em: https://www.youtube.com/watch?v=2fGCHFPVAao__Publicado em 21/04/2014. Consultado em julho de 2014.

YOUTUBE. Emocionante e linda Homenagem ao pequeno Bernardo Uglione Boldrini. Disponível em: https://www.youtube.com/watch?v=tzYzkma4dN8. Publicado em 21/04/2014. Consultado em julho de 2014.

YOUTUBE. In memoriam do pequeno Bernardo Uglion Boldrini. Disponível em: https://www.youtube.com/watch?v=U88ZCSH_bv4. Publicado em 25/05/2014. Consultado em julho de 2014.

YOUTUBE. Três Passos chora por Bernardo Boldrini. Disponível em: https://www.youtube.com/watch?v=skqOiFqW0y8. Publicado em

21/04/2014. Consultado em julho de 2014. 